\title{
Molecular characterization of extended-spectrum beta-lactamases in Enterobacteriaceae from patients of two hospitals in Saxony, Germany
}

\author{
Joachim Schmitt, Enno Jacobs and Herbert Schmidt† \\ Institute of Medical Microbiology and Hygiene, Technical University of Dresden, Fetscherstrasse \\ 72, Dresden, Germany
}

Correspondence

Herbert Schmidt

hschmidt@uni-hohenheim.de

Received 10 April 2006

Accepted 25 October 2006

\begin{abstract}
Between January and September 2003, 39 isolates of the family Enterobacteriaceae with phenotypically positive Vitek 1 extended-spectrum beta-lactamase (ESBL) test results were collected, originating from patients of two hospitals in Saxony, Germany. Plasmid DNA was isolated and screened by PCR for the presence of genes encoding beta-lactamases of SHV, TEM and CTX-M types. To differentiate ESBL and non-ESBL among SHV and TEM genes, detailed analysis of PCR products was performed. Twenty-four strains carried SHV-2, SHV-5 or SHV-12 genes. In a further 11 strains a CTX-M gene was detected. The CTX-M genes could be affiliated to the CTX-M-1 and CTX-M-9 cluster by RFLP analysis. In the case of four Klebsiella oxytoca isolates, hyperproduction of the chromosomal beta-lactamase $\mathrm{K} 1$ was inferred, because genes of the above-mentioned types were not detected. The strains contained plasmid DNA between 45 and $160 \mathrm{~kb}$ in size. Common plasmid restriction patterns among SHV-5 producers provided evidence of horizontal spread. Twenty strains had a MIC for cefotaxime of $\leqslant 4 \mathrm{mg} \mathrm{I}^{-1}, 18$ strains had the same MIC for ceftazidime, and nine strains had this MIC of $>4 \mathrm{mg} \mathrm{l}^{-1}$ for both antibiotics. The ESBL phenotypes often coincided with ciprofloxacin or gentamicin resistance.
\end{abstract}

\section{INTRODUCTION}

Enterobacterial resistance against oxyimino-cephalosporins such as ceftriaxone and ceftazidime (CAZ) is a growing problem in the treatment of nosocomial infections, and is often caused by the production of extended-spectrum betalactamases (ESBLs) (Paterson et al., 2003). ESBLs are frequently identified in Klebsiella pneumoniae and Escherichia coli (Gniadkowski et al., 1998a), but also in other species, such as Citrobacter spp., Enterobacter spp. and Pseudomonas aeroginosa. ESBL producers have been found worldwide (Jacoby \& Medeiros, 1991). The general substrate profile of ESBLs includes penicillins, cephalosporins and monobactams. More than 100 ESBL variants from different types are known. The most abundant types are represented by SHV, TEM, OXA and CTX-M (Gniadkowski, 2001). All types except OXA belong to Ambler class A or Bush group 2be. OXA enzymes belong to class D or group 2d (Bush, 2001). While TEM- and SHV-type ESBLs have developed from their ancestors SHV-1 and TEM-1/-2 by point

tPresent address: Institute of Food Science and Biotechnology, Department of Food Microbiology, University of Hohenheim, Garbenstrasse 28, D-70599 Stuttgart, Germany.

Abbreviations: CAZ, ceftazidime; CFP, cefepime; CIPR, ciprofloxacin; CTX, cefotaxime; ESBL, extended-spectrum beta-lactamase; GENT, gentamicin; ICU, intensive care unit; IMIP, imipenem; PIP, piperacillin; PITA, piperacillin/tazobactam. mutations, the origin of the other enzymes is less clear. The plasmid-encoded TEM-1/-2 enzymes are widespread and are the cause of resistance to broad-spectrum penicillins in many Gram-negative rods, such as E. coli, Neisseria gonorrhoeae and Haemophilus influenzae (Livermore, 1995). SHV-1 is the chromosomally encoded beta-lactamase K2 from K. pneumoniae, but has also been found to be plasmid encoded in other species (Chang et al., 2001). For both TEM-1 and SHV-1, an association with transposons is recognized (Heritage et al., 1999). Some enzymes of the CTX-M type are identical or similar to species-specific betalactamases from Kluyvera spp. (Bonnet, 2004). The detection of ESBL production in microbial diagnostics is especially problematic, since such micro-organisms often seem to be susceptible to broad-spectrum cephalosporins in vitro (Gniadkowski, 2001). A failure to detect ESBLs and subsequent treatment with oxyimino-cephalosporins are associated with a higher risk of therapy failure (Paterson et al., 2001). Higher mortality rates have also been described (Kim et al., 2002). Although the first ESBLs were discovered in Germany (Kliebe et al., 1985), investigations of ESBLs in Germany have not yielded consistent results (Bauernfeind et al., 1993; Babini \& Livermore, 2000). In order to get information on the regional spread of ESBL, we characterized 39 strains that were isolated from patients in two local hospitals and that tested ESBL positive with a Vitek 1 ESBL test (bioMérieux). 


\section{METHODS}

Bacterial strains. The strains included in this study were isolated between January and September 2003 from specimens of patients hospitalized at two local hospitals in the region of Dresden, designated hospital A and hospital B. The isolates showed decreased susceptibility to oxyimino-cephalosporins and were phenotypically tested for ESBL production by the Vitek 1 ESBL test (bioMérieux). ESBL test-positive strains were collected and stored in glycerol cultures. In total, from 37 patients, $21 \mathrm{~K}$. pneumoniae strains, $10 \mathrm{E}$. coli strains, six $K$. oxytoca strains and one strain each of Citrobacter freundii and Enterobacter aerogenes were isolated.

Transfer of resistance determinants. In order to investigate the conjugative transfer of resistance determinants, broth mating experiments were performed. The plasmid-free, rifampicin-resistant $E$. coli strain A15 $\mathrm{R}^{-}$was used as an acceptor (Elwell \& Falkow, 1986). This strain was kindly provided by Branka Bedenič, 'A. Stampar' Medical School, University of Zagreb, Croatia. Overnight LuriaBertani (LB) broth cultures of the acceptor and the respective donor strain were mixed in a ratio of $1: 2$ and incubated for $18 \mathrm{~h}$ at $37^{\circ} \mathrm{C}$ without shaking. The selection of transconjugants was performed by spreading $100 \mu \mathrm{l}$ of the mixture onto MacConkey agar plates containing $200 \mathrm{mg}$ rifampicin $1^{-1}$ as well as $2 \mathrm{mg} \mathrm{CAZ} 1^{-1}$ or cefotaxime (CTX). As some K. pneumoniae strains developed rifampicin resistance during mating, colonies were subcultured on citrate agar (Simmons citrate agar, Oxoid) to detect citrate-positive, rifampicinresistant $K$. pneumoniae donor strains.

Preparation of plasmid DNA. Plasmid DNA was obtained using a modified alkaline-lysis method (Sambrook et al., 1989), with slight modifications. Briefly, a further purification step with phenol/ chloroform was added before DNA precipitation in 2-propanol. In some strains, the quality of this preparation was not sufficient for the subsequent restriction analysis, probably because of the presence of capsular polysaccharides. In these cases, bismuth (III) pentahydrate (Sigma-Aldrich) and sodium salicylate were added to the LB medium before incubation in final concentrations of 0.5 and $2.5 \mathrm{mM}$, respectively, as described by Domenico et al. (1992). After incubation and before alkaline lysis, EDTA $(\mathrm{pH} \mathrm{10)}$ was added to a final concentration of $5 \mathrm{mM}$ to bind bismuth ions. Unlike the method of Domenico et al. (1992), the treatment with a detergent was omitted. Plasmids were separated on a $0.8 \%(\mathrm{w} / \mathrm{v})$ agarose gel in Tris/borate/EDTA buffer for $1.5 \mathrm{~h}$ at $120 \mathrm{~V}$.

Restriction of plasmid DNA. Aliquots of $10 \mu$ of the plasmid DNA preparation were subjected to restriction with $1 \mu \mathrm{l}$ EcoRI

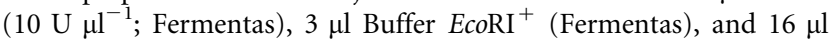
nuclease-free deionized water for $2 \mathrm{~h}$ at $37^{\circ} \mathrm{C}$. DNA was separated on a $1 \%(\mathrm{w} / \mathrm{v})$ agarose gel for $17 \mathrm{~h}$ at $30 \mathrm{~V}$ together with the molecular mass standard peqGOLD DNA-Sizer IX (Peqlab Biotechnologie).

PCR. In order to detect genes encoding Ambler class A beta-lactamases (bla), a standard PCR was performed with plasmid DNA as a template. For amplification of genes encoding SHV beta-lactamases $\left(b l a_{\mathrm{SHV}}\right)$, primers MN I (5'-CGC CGG GTT ATT CTT ATT TGT CGC-3') and MN II (5'-TCT TTC CGA TGC CGC CGC CAG TCA-3') were used (Nüesch-Inderbinen et al., 1996). The thermal cycling conditions used for the PCR with these primers included 30 cycles at $94{ }^{\circ} \mathrm{C}$ for $30 \mathrm{~s}, 68^{\circ} \mathrm{C}$ for $60 \mathrm{~s}$, and 72 for $60 \mathrm{~s}$, with a final extension of $72{ }^{\circ} \mathrm{C}$ for $300 \mathrm{~s}$. The $1016 \mathrm{bp}$ PCR product contained the entire ORF. For amplification of genes encoding TEM beta-lactamases $\left(b l a_{\text {TEM }}\right)$, primers TEM-F ( $5^{\prime}$-ATA AAA TTC TTG AAG ACG AAA- $\left.3^{\prime}\right)$ and TEM-R (5'-GAC AGT TAC CAA TGC TTA ATC A$\left.3^{\prime}\right)$ were used with thermal cycling conditions as described elsewhere (Wu et al., 2001). The $1080 \mathrm{bp}$ amplicon reached from $214 \mathrm{bp}$ upstream of the start codon to the stop codon. In order to detect genes for CTX-M beta-lactamases $\left(b l a_{\mathrm{CTX}-\mathrm{M}}\right)$, a PCR was performed with primers and conditions described elsewhere (Edelstein et al., 2003). The amplicon is a $544 \mathrm{bp}$ intragenic fragment. Ten microlitres of PCR product was electrophoresed in a $1 \%(\mathrm{w} / \mathrm{v})$ agarose gel for $1 \mathrm{~h}$ at $140 \mathrm{~V}$ together with a Smartladder DNA standard (Eurogentec).

DNA sequencing. Since the above-mentioned MN and TEM primers are specific for all $b l a_{\mathrm{SHV}}$ and $b l a_{\mathrm{TEM}}$, including the non-ESBL variants, it was necessary to sequence the PCR products. For this purpose, PCR products were purified with a QIAquick PCR purification kit (Qiagen). Sequencing reactions were performed with the primers used for PCR detection using a BigDye Terminator Cycle Sequencing Ready Reaction Premix (Applied Biosystems). After purification with AutoSeq-G50 columns (Amersham Biosciences), products of the sequencing reaction were subjected to direct sequencing on an ABI Prism 377 automated sequencer (Applied Biosystems). The sequences were analysed using the program Bioedit (Hall, 1999). Chromatograms were visually inspected for double peaks as signs of the presence of different bla genes from the same type.

Differentiation between bla $a_{\text {ESBL-SHV }}$ and $b / a_{\text {non-ESBL-SHV }}$ in a PCR product. In the case of double peaks within the chromatograms of bla $a_{\mathrm{SHV}}$ sequences, a $40 \mu \mathrm{l}$ aliquot of the corresponding

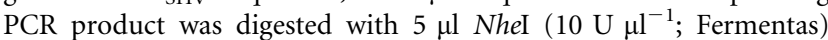
and $5 \mu \mathrm{l} 10 \times$ Buffer $\mathrm{Y}^{+} /$Tango (Fermentas) with BSA for $3 \mathrm{~h}$ at $37^{\circ} \mathrm{C}$. Digested DNA was separated on $1.5 \%(\mathrm{w} / \mathrm{v})$ agarose gels for $2 \mathrm{~h}$ at $140 \mathrm{~V}$. As described elsewhere (Nüesch-Inderbinen et al., 1997), most $b l a_{\mathrm{ESBL}-\mathrm{SHV}}$ genes contain the NheI restriction site, in contrast to $b l a_{\text {non-ESBL-SHV }}$ genes. Thus, both fragments could be separated from each other. The $b l a_{\text {non-ESBL-SHV }}$ fragment was extracted from the gel under visualization with UV light. The extraction was performed using a QIAquick Gel Extraction kit (Qiagen), according to the guidelines of the manufacturer. The product was directly subjected to sequencing, as described above, without any further purification. In this way, mixed sequence signals at characteristic positions inside ORFs of some SHV sequences could be assigned to ESBL and non-ESBL enzymes, respectively.

RFLP analysis of bla $\mathbf{c}_{\text {cTX-M. }}$ A further subgrouping of $b l a_{\text {CTX-M }}$ was performed according to Edelstein et al. (2003). For this purpose, $10 \mu \mathrm{l}$ of the products of CTX-M-specific PCR were digested with $0.9 \mu \mathrm{l}$ PstI $\left(10 \mathrm{U}^{-1}\right), \quad 0.2 \mu \mathrm{l} \quad$ PvuII $\left(20 \mathrm{U}^{-1} \mathrm{l}^{-1}\right), 2 \mu \mathrm{l} \quad 10$-fold NEBuffer 3 (enzymes and buffer, New England BioLabs) and $6.9 \mu \mathrm{l}$ nuclease-free distilled water at $37^{\circ} \mathrm{C}$ for $3 \mathrm{~h}$. Restriction fragments were electrophoresed in a $3 \%(\mathrm{w} / \mathrm{v})$ agarose gel for $2 \mathrm{~h}$ at $140 \mathrm{~V}$ together with the DNA standard Smartladder SF (Eurogentec).

Determination of MICs. In order to phenotypically characterize the resistance properties of the strains, MICs were determined for CTX (Aventis), CAZ (GlaxoSmithKline), cefepime (CFP; BristolMyers Squibb), piperacillin (PIP; Ratiopharm) in combination with tazobactam (Wyeth Pharma), imipenem (IMIP; Merck, Sharp and Dohme), gentamicin (GENT; Merck) and ciprofloxacin (CIPR; Bayer). MICs were determined by the agar dilution method on Mueller-Hinton agar plates containing antibiotics in concentrations of a geometric series according to the DIN 58940-6 guidelines of the German Institute for Standardization (Deutsches Institut für Normung, 1989). MIC determination for the PIP/tazobactam (PITA) combination was tested using a fixed concentration of $4 \mathrm{mg}$ tazobactam $1^{-1}$ and varying concentrations of PIP.

\section{RESULTS}

The Department of Medical Microbiology and Hygiene is responsible for clinical microbiological diagnostics of patients from all wards of two hospitals in Dresden and 
its vicinity. The origins of the individual strains are listed in Table 2. Most strains (19) were isolated from clinical specimens originating from patients' airways, followed by urine (12), skin (three), body cavities (three) and blood (two). All 39 strains belonged to the family Enterobacteriaceae.

\section{SHV-specific PCR and sequencing}

SHV-specific PCR revealed $b l a_{\mathrm{SHV}}$ genes in all $21 \mathrm{~K}$. pneumoniae, in two E. coli and one each in K. oxytoca, Ent. aerogenes and C. freundii isolates. The DNA sequences of the PCR products showed seven alleles encoding SHV-2, nine encoding SHV-5, four encoding SHV-12 and one each encoding SHV-1 and SHV-28. The latter two enzymes are not known to mediate extended-spectrum resistance. However, SHV-28 has been described in another ESBLconferring strain (Ndugulile et al., 2005), and has been suggested to confer ESBL-mediated resistance.

A further four raw DNA sequences contained mixed signals in the respective electropherograms at characteristic positions, all at amino acid position 238 according to the numbering provided by Ambler (Ambler et al., 1991). This problem was resolved by NheI restriction endonuclease digestion, as described above. It resulted in the detection of two SHV alleles in a single strain, as follows: $b l a_{\mathrm{SHV}-2}$ paired with $b l a_{\mathrm{SHV}-1}$ twice; $b l a_{\mathrm{SHV}-2}$ paired with $b l a_{\mathrm{SHV}-28}$ once; $b l a_{\mathrm{SHV}-12}$ paired with $b l a_{\mathrm{SHV}-1}$ once. The sequence of $K$. pneumoniae KP01 revealed a non-functional start codon, damaged by a $\mathrm{T}$ to $\mathrm{G}$ mutation; apart from that it was identical to the deduced SHV-1 sequence. In conclusion, the ESBL phenotype could be explained by SHV ESBL production in 24 strains only, in spite of a positive SHV $\mathrm{PCR}$ result in 26 cases. Ent. aerogenes EA05 (single bla $a_{\mathrm{SHV}-1}$ ),
K. pneumoniae KP12 (single bla $a_{\mathrm{SHV}-28}$ ) and KP01 (defective start codon) putatively express other resistance mechanisms in addition to the production of SHV-type enzymes. Coding and non-coding genetic polymorphisms are summarized in Table 1. Since all ESBL genes from the same SHV type were identical among themselves, only one representative example is shown for all strains of the same ESBL type.

\section{TEM-specific PCR}

As mentioned above, only in 24 strains could the ESBL characteristic be explained by the presence of SHV ESBL genes. The genetic origin of ESBL production in the remaining 15 strains was therefore located in genes of other types. Accordingly, all strains were screened for further genes. A TEM-specific primer set was used to detect $b l a_{\mathrm{TEM}}$ genes. In 12 strains, $b a_{\text {TEM }}$ genes could be detected in this way. Sequencing of the PCR products with the same primers used for PCR revealed reliable chromatograms up to Ambler position 285. All $12 \mathrm{PCR}$ products consisted of $b l a_{\mathrm{TEM}}$ sequences identical to published $b l a_{\mathrm{TEM}-1}$ sequences (Backman et al., 2000). They originated from four SHV-5 producers (KP09, KP13, KP19, KP22), three SHV-12 producers (KP03, KP10, EC29), and two K. oxytoca and four E. coli not producing SHV enzymes. The ESBL phenotypes could not be explained by the presence of $b l a_{\mathrm{TEM}}$ genes in this survey.

\section{CTX-M-specific PCR and RFLP analysis of PCR products}

As ESBLs from type CTX-M have been increasing in frequency in Western and Central Europe for some years (Alobwede et al., 2003), further screening for this type was performed. With respect to the genetic heterogeneity within

Table 1. Coding and silent mutations in ORFs of sequenced blasHv genes compared with SHV-1 (GenBank accession no. AF124984)

\begin{tabular}{|c|c|c|c|c|c|c|c|c|c|c|}
\hline Isolate ${ }^{\star}$ & Enzyme & \multicolumn{9}{|c|}{ Codon $\dagger$} \\
\hline КР02, КР03 & SHV-1 & - & - & CAT & CTG & CGA & - & GAA & ATC & - \\
\hline KP23 & SHV-1 & - & - & - & - & - & - & - & - & - \\
\hline KP37 & SHV-2 & - & - & - & - & - & AGC & - & - & - \\
\hline KP34 & SHV-5 & - & - & - & - & - & AGC & AAG & - & - \\
\hline $\mathrm{KO} 26$ & SHV-12 & - & CAA & - & CTG & - & AGC & AAG & - & ACG \\
\hline
\end{tabular}

${ }^{\star}$ Isolates are abbreviated as follows: KP, K. pneumoniae; EA, Ent. aerogenes, KO, K. oxytoca.

$\dagger$ The amino acid residue (in the case of a coding mutation, both amino acids are shown), followed by the position according to the Ambler numbering scheme (Ambler et al., 1991). The sequence of a prototype SHV-1 sequenced by Rice et al. (1999) is shown above each column, and identity to that sequence is marked by ' - '. Mutated nucleotides are shown in bold type.

$¥$ At this codon, two possible mutations occur: a coding mutation at the first position and a non-coding one at the third position. 
Table 2. Overview over all strains, identified enzyme(s), ward of isolation, MICs and assigned resistance phenotype

Abbreviations: anaesthes., anaesthesiology; HA, hospital A; HB, hospital B.

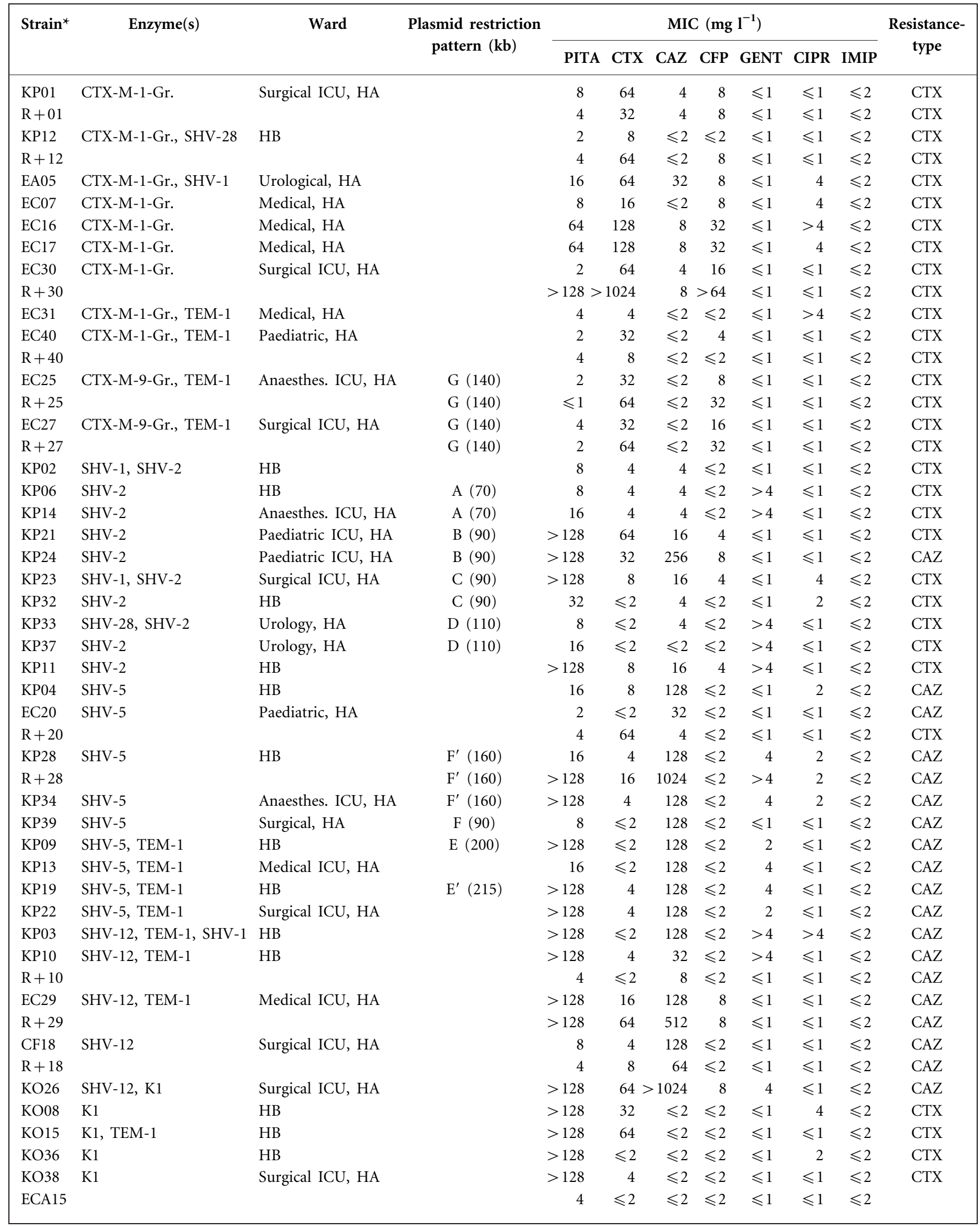

${ }^{\star}$ Transconjugant strains are named $\mathrm{R}+$. 
the group of bla $a_{\mathrm{CTX}-\mathrm{M}}$, a subgrouping into five clusters (CTX-M-1, CTX-M-2, CTX-M-8, CTX-M-9 and recently discovered CTX-M-25) was performed using sequence homology criteria (Bonnet, 2004). To detect the presence of CTX-M ESBL genes in the strains used in this study, a

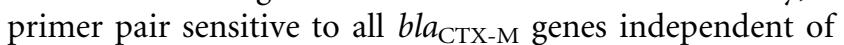
cluster affiliation was chosen. However, this primer pair produces false-positive results for the species-specific chromosomally encoded beta-lactamase (bla) genes of some Gram-negative strains (Edelstein et al., 2003). Among the species used in this work, only the K. oxytoca strains with their chromosomal beta-lactamase K1 encoded by $b l a_{\mathrm{OXY}}$ were affected. In fact, an amplicon could be obtained by this PCR analysis from DNA preparations from all these strains. In addition, a positive result could be obtained from eight E. coli, two K. pneumoniae and the Ent. aerogenes strains. For all non- $K$. oxytoca strains, RFLP analysis of PCR products was performed in order to obtain information about the cluster affiliation of the genes found. Restriction patterns were compared with the expected ones described in the original publication (Edelstein et al., 2003). For the new cluster of CTX-M-25-like enzymes (CTX-M-25 and CTX-M-26), which was not discovered at the date of development of the method, a restriction map was created with Bioedit. The digestion of such a CTX-M-25-like PCR product would result in fragments of 422 and $120 \mathrm{bp}$ in length, which can be distinguished from the restriction patterns of the other clusters. The PCR products of all strains, except two E. coli strains, displayed the fragment of a bla $a_{\text {CTX-M-1 }}$-like gene. Two E. coli isolates, EC25 and EC27, carried a gene belonging to the CTX-M-9 cluster. The PCR products of $K$. oxytoca strains were sequenced using the same primer pair as for PCR detection. This procedure was performed to identify mixed signals in sequence chromatograms that would have occurred in the case of the simultaneous presence of a $b l a_{\mathrm{OXY}}$ encoding $\mathrm{K} 1$ and a $b l a_{\text {CTX-м. }}$. All sequences of $K$. oxytoca strains were clear cut in encoding K1. Table 2 shows the detected enzyme genes, the plasmid restiction patterns and the MIC values for all strains.

\section{Mating experiments}

Transconjugants could be obtained from 11 strains only. If a mating experiment was unsuccessful, it was repeated with CTX or CAZ as selective agent. Transconjugant plasmid DNA was obtained and PCRs were performed in the same way as in the case of donor strains. Two SHV-5 producers, three SHV-12 producers, four of the strains producing a CTX-M-1-like enzyme and both strains with the bla $_{\mathrm{CTX}-\mathrm{M}-9^{-}}$ like gene transferred their ESBL gene to E. coli A15 R ${ }^{-}$. Five of the 11 donors carried an additional TEM-1, but only one of them co-transferred it to the acceptor strain. SHV PCR of plasmid DNA from transconjugants of two CTX-M producers with an additional $b l a_{\text {non-ESBL-SHV }}$ was negative.

\section{Analysis of plasmids}

In order to detect the presence of common restriction bands among plasmids of strains with the same ESBL type and among their transconjugants, plasmid DNA was isolated and digested with EcoRI. Five different restriction patterns were found among SHV-2 producers, the band sizes of which ranged from approximately 70 to $130 \mathrm{~kb}$. Four of the restriction patterns appeared to be paired. Two of the pairs with identical plasmid restriction patterns were isolated from the same departments within hospital A. In the case of the other two paired restriction patterns, one pair of strains was isolated at hospital A and one at hospital B. Analysis of unrestricted plasmid DNA of SHV5 producers revealed at least two single bands, which allowed us to infer the presence of at least two independent plasmids. All restriction patterns of SHV-5-producing strains plasmid DNA had common elements, which can be inferred from Fig. 1. Strains EC20 and KP28 were two SHV-5 producers from which transconjugants could be obtained. All restriction bands of the donor pattern were present in transconjugants in both cases (110 and $160 \mathrm{~kb}$ ). SHV-5-producing strains were isolated at both hospitals. Among SHV-12-producing strains, no common plasmid DNA restriction pattern could be observed, other than a common $6 \mathrm{~kb}$ band in KP10, CF18 and KO26. Plasmid sizes ranged from 45 to $160 \mathrm{bp}$. The CTX-M producers EC07, EC16 and EC17 had a common restriction pattern, probably because of three common bands in electrophoresis of their undigested plasmid DNA. In addition to these three bands there were a further one at EC07, two at EC16 and four at EC17. All three strains were isolated from the same patient of hospital A on two different dates. The two strains EC25 and EC27 producing a CTX-M-9-like beta-lactamase had an identical plasmid restriction profile $(\sim 140 \mathrm{~kb})$. Both were isolated from intensive care units (ICUs) of hospital A. As was

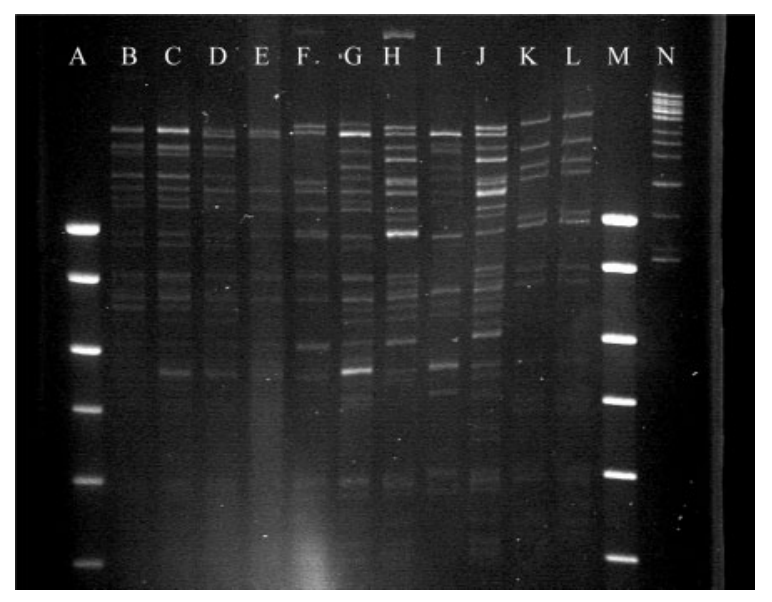

Fig. 1. Restriction patterns of plasmid DNA of SHV-5-carrying strains after EcoRI digestion show partly common bands. Lanes: $A$ and M, DNA-Sizer Smartladder (10, 8, 6, 5, 4, $3 \mathrm{~kb}$ ); $\mathrm{B}, \mathrm{R}+28$; C, KP28; D, KP34; E, KP39; F, KP22; G, KP04; H, KP09; I, KP13; J, KP19; K, EC20; L, R+20; N, DNA-Sizer IX $(48,38,33,29,24,23,19,17,15,12,10,8 \mathrm{~kb})$. 
the case with the SHV-12 producers, there was no common restriction pattern observable upon gel electrophoresis of digested plasmid DNA of the other CTX-M-producing strains. Total plasmid DNA of the strains ranged from approximately 40 to $90 \mathrm{~kb}$ in size.

\section{Determination of MICs}

The MICs for selected antibiotics are summarized in Table 2. Depending on their MICs, a resistance type was assigned to CTX (MIC for CAZ greater than twofold the MIC for CTX) and CAZ (MIC for CAZ greater than fourfold the MIC for CTX) (Bedenič et al., 2001). The resistance type correlated with ESBL genotype as follows. All strains producing SHV-2 and CTX-M beta-lactamases were assigned to a CTX resistance type, while SHV-5- and SHV-12-producing strains displayed a CAZ type. KP24 and the transconjugant from EC20, $\mathrm{R}+20$, were exceptions. Surprisingly 10 strains had a MIC $\leqslant 2 \mathrm{mg} \mathrm{l}^{-1}$ for CTX and 12 had the same for CAZ. The SHV-2 producer KP37 and the $\mathrm{K} 1$ carrier $\mathrm{KO} 36$ did not grow at this concentration, either on CTX or CAZ. In summary, 20 strains appeared to be susceptible to CTX (MIC $\leqslant 4 \mathrm{mg} \mathrm{l}^{-1}$ ) and 19 to CAZ $\left(\mathrm{MIC} \leqslant 4 \mathrm{mg} \mathrm{l}^{-1}\right)$. Nine strains were susceptible to both antibiotics according to the German standard tests. CFP was revealed to be more effective against ESBL producers; only four strains were resistant. The MICs towards PITA were distributed bimodally: 20 strains had a MIC between $2+4$ and $16+4 \mathrm{mg} \mathrm{l}^{-1}$, while 17 strains still grew at concentrations of $512+4 \mathrm{mg} \mathrm{l}^{-1}$. Twelve strains were resistant towards GENT (MIC $\geqslant 4 \mathrm{mg}$ GENT ${ }^{-1}$ ). KP28 transferred this resistance together with an ESBL to the donor strain as well as reduced susceptibility towards CIPR

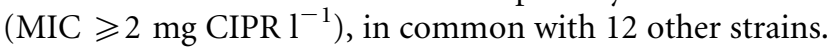
All strains were completely susceptible to IMIP (MIC $\leqslant 2 \mathrm{mg}_{\mathrm{IMIP}} \mathrm{l}^{-1}$ ).

\section{DISCUSSION}

SHV-2- and SHV-5-type ESBLs are spread worldwide, and their occurrence in Germany has already been known for some time (Bauernfeind et al., 1993). The SHV-12 allele has usually been found in Asia (Kim et al., 2005; Liu et al., 2004). It has also been detected in the other four continents (De Champs et al., 2004; Nüesch-Inderbinen et al., 1996; Mulvey et al., 2004; Howard et al., 2002). All bla $a_{\mathrm{SHV}-12}$ genes found here carried the same characteristic silent mutations (Table 1) as the one first described (Nüesch-Inderbinen et al., 1996) and all the other sequenced genes of this type published in the NCBI database. Amongst the SHV-12 producers analysed in this study we found no common plasmid restriction patterns. Probably, $b l a_{\mathrm{SHV}-12}$ is part of a worldwide-disseminating mobile element. Besides K. pneumoniae, C. freundii (CF18), E. coli (EC29) and K. oxytoca (KO26) also contain SHV-12 genes. Moreover, the SHV-12 gene has been found in Serratia liquefaciens (GenBank accession no. AY273807), Enterobacter cloacae (AF462395) and Acinetobacter baumanii (AY259163). Although first identifications of CTX-M-type ESBLs occurred about 15 years ago (Bauernfeind et al., 1990), for years, dissemination has only been known in endemic areas of Asia, Southern America and Eastern Europe (Bonnet, 2004). Recently, dissemination of this ESBL type has been observed (Coque et al., 2002; Alobwede et al., 2003). Detection of CTX-M-type enzymes in Dresden underlines this trend. Most of the strains carried genes for a CTX-M-1-like enzyme. For CTX-M-3, the most important representative of this group, epidemic occurrence in Poland (Gniadkowski et al., 1998b) and Russia (Edelstein et al., 2003) is known. In those two studies, the two CTX-M-9-like carriers EC25 and EC27 had identical plasmid restriction profiles, in contrast to the CTX-M-1-like enzyme carriers found in this study. Both were isolated from ICUs of hospital A, implicating cross-infection. Their $160 \mathrm{~kb}$ plasmid could be transferred in vitro, suggesting further dissemination of this enzyme type. The most disseminated representative of this enzyme type, CTX-M-14, has already been found in Spain (Coque et al., 2002), France and the UK (Alobwede et al., 2003).

Most of the strains able to transfer their resistance in vitro were SHV-12 or CTX-M producers, implicating the role of transconjugation in dissemination, while transconjugants could not be obtained from SHV-2 producers. A similarly low transconjugation success was reported from a molecular survey of SHV-producing Klebsiella strains in Switzerland (Nüesch-Inderbinen et al., 1996). In that study, 26 of 37 $b l a_{\mathrm{SHV}^{-}}$-carrying strains were unable to transfer ESBL genes. In our survey, 19 of 24 strains did not transfer the ESBLs. In contrast, six of 11 CTX-M carriers were shown to transconjugate the CTX-M genes. Probably, clonal expansion is a more important mechanism in the dissemination of SHV-2 and SHV-5 genes.

All but one of the non-ESBL SHV sequences $\left(b a_{\mathrm{SHV}-1}\right.$ in KP23) carried silent mutations that were different to those found in ESBL genes, making co-evolution improbable (Table 1). SHV-28 had already been identified from China (GenBank accession nos AF538324 and AY299299). This allele differs from SHV-1 by an amino acid substitution at position 7 according to Ambler's standard numbering scheme for class A beta-lactamases (Ambler et al., 1991). Since the mature protein starts with Ambler position 26 compared to SHV-1 (Péduzzi et al., 1989), there should not be any difference either in biochemical properties or in isoelectric point. The detected SHV-1 from Ent. aerogenes EA05 must have been plasmid encoded, because from this species only a chromosomally encoded Ambler class $\mathrm{C}$ betalactamase $(\mathrm{AmpC})$ is known, which is produced only in small amounts, but is inducible. The same applies to $C$. freundii. The beta-lactamase $\mathrm{K} 1$ is the chromosomally encoded class A beta-lactamase of $K$. oxytoca. It is encoded by two genes, $b l a_{\mathrm{OXY}-1}$ and $b l a_{\mathrm{OXY}-2}$ (Mammeri et al., 2001). Intrinsically, K1 mediates only moderate resistance towards penicillins. However, at present, up to $20 \%$ of isolates hyperproduce this enzyme in Europe. The 
consequence is a significant resistance towards ceftriaxone, CTX and aztreonam. This must be the case with the $K$. oxytoca strains in this study, as one can observe typical signs of $\mathrm{K} 1$ hyperproduction in the resistance patterns, such as resistance to PITA and at least reduced susceptibility to CTX (Table 2) (Livermore, 1995). Hyperproduction is more usual with $b l a_{\mathrm{OXY}-2}$-encoded enzymes, and can be caused by point mutations within the promoter sequence (Jeong et al., 2001; Fournier et al., 1995). In the case of K. oxytoca KO26, in which an SHV-12 beta-lactamase had already been identified, $\mathrm{K} 1$ was encoded by $b l a_{\mathrm{OXY}-1}$. In the case of the other four K. oxytoca strains, $\mathrm{K} 1$ was encoded by $b l a_{\mathrm{OXY}-2}$. With respect to the Vitek 1 ESBL test as performed in our department, it is known that it cannot distinguish between a K1 hyperproducer and a 'classical' ESBL carrier (Leversteinvan Hall et al., 2002). Although K1 was assigned to group 2be (ESBL) within the functional beta-lactamase classification scheme of Bush-Jacoby-Medeiros (Bush et al., 1995), in fact, ESBL detection in K1 hyperproducers represents a false-positive result, because it is not necessary to regard such strains as resistant to all cephalosporins independently of their resistance patterns, as is the case with ESBL carriers. Moreover, these strains cannot transfer their resistance horizontally. $\mathrm{KO} 26$ demonstrates that $K$. oxytoca strains are potential ESBL producers, and false-negative ESBL test results should be regarded as more dangerous than falsepositive results in that regard. Paterson et al. (2001) have described the higher risk of therapy failure in the treatment by oxyimino-cephalosporins of infections with ESBLproducing strains, even if the strains appear to be susceptible in vitro. The number of strains having a MIC defined as susceptible to CAZ or CTX underlines the necessity to test with both antibiotics and cut-offs below $4 \mathrm{mg} \mathrm{l}^{-1}$. Experts suggest $2 \mathrm{mg} \mathrm{l}^{-1}$ (Witte \& Mielke, 2003; Geiss et al., 2003). CFP seems to be more effective than CTX and CAZ. One should consider the possibility of the decreasing efficacy of this beta-lactam due to inoculum effects and changes in the outer-membrane protein profile during therapy, particularly in the case of infections that are connected with high bacterial inocula in vivo, such as endocarditis, meningitis, septic arthritis, osteomyelitis, abscesses and other deepseated infections (Thomson \& Moland, 2001). The bimodal distribution of MICs towards PITA has recently been observed and investigated (Babini et al., 2003). It is caused by titration effects when testing with fixed concentrations of tazobactam. The distribution becomes unimodal if the ratio of piperacillin to tazobactam is kept constant at $1: 8$. Babini et al. (2003) emphasize the general susceptibility of ESBLs towards inhibition with tazobactam. If strains are susceptible to PITA in vitro, it should be considered as a therapeutic option. The prevalence of ESBL-producing strains decreases if hospitals reduce their use of oxyiminocephalosporins in favour of beta-lactam inhibitor plus piperacillin (Gniadkowski, 2001; Bradford, 2001). In our survey ESBL production coincided with fluoroquinolone ( $28 \%$ reduced susceptibility to CIPR) and aminoglycoside resistance ( $30 \%$ GENT resistance in this survey), similar to results seen elsewhere. Thus, fewer therapeutic options remain for treatment, and that is one reason why the emergence of ESBLs should be controlled in the future. In this context, the importance of molecular diagnostics will increase, as they are a more reliable method than phenotypic testing.

\section{REFERENCES}

Alobwede, I., M'Zali, F. H., Livermore, D. M., Heritage, J., Todd, N. \& Hawkey, P. M. (2003). CTX-M extended-spectrum $\beta$-lactamase arrives in the UK. J Antimicrob Chemother 51, 470-471.

Ambler, R. P., Coulson, A. F. W., Frère, J. M., Ghuysen, J.-M., Joris, B., Forsman, M., Levesque, R. C., Tiraby, G. \& Waley, S. G. (1991). A standard numbering scheme for the class A $\beta$-lactamases. Biochem $J$ 276, 269-272.

Babini, G. S. \& Livermore, D. M. (2000). Antimicrobial resistance amongst Klebsiella spp. collected from intensive care units in Western and Southern Europe in 1997-1998. J Antimicrob Chemother 45, 183-189.

Babini, G. S., Yuan, M., Hall, L. M. C. \& Livermore, D. M. (2003). Variable susceptibility to piperacillin/tazobactam amongst Klebsiella spp. with extended-spectrum $\beta$-lactamases. J Antimicrob Chemother 51, 605-612.

Backman, A., Orvelid, P., Vazquez, J. A., Skold, O. \& Olcen, P. (2000). Complete sequence of a beta-lactamase-encoding plasmid in Neisseria meningitidis. Antimicrob Agents Chemother 44, 210-212.

Bauernfeind, A., Grimm, H. \& Schweighart, S. (1990). A new plasmidic cefotaximase in a clinical isolate of Escherichia coli. Infection 18, 294-298.

Bauernfeind, A., Rosenthal, E., Eberlein, E., Holley, M. \& Schweighart, S. (1993). Spread of Klebsiella pneumoniae producing SHV-5 beta-lactamase among hospitalized patients. Infection 21, $18-22$.

Bedenič, B., Randegger, C., Boras, A. \& Hächler, H. (2001). Comparison of five different methods for detection of SHV extended-spectrum $\beta$-lactamases. J Chemother 13, 24-33.

Bonnet, R. (2004). Growing group of extended-spectrum betalactamases: the CTX-M enzymes. Antimicrob Agents Chemother 48, $1-14$.

Bradford, P. A. (2001). Extended-spectrum $\beta$-lactamases in the 21 st century: characterization, epidemiology, and detection of this important resistance threat. Clin Microbiol Rev 14, 933-951.

Bush, K. (2001). New $\beta$-lactamases in Gram-negative bacteria: diversity and impact on the selection of antimicrobial therapy. Clin Infect Dis 32, 1085-1089.

Bush, K., Jacoby, G. A. \& Medeiros, A. A. (1995). A functional classification scheme for beta-lactamases and its correlation with molecular structure. Antimicrob Agents Chemother 39, 1211-1233.

Chang, F.-Y., Siu, L. K., Fung, C.-P., Huang, M.-H. \& Ho, M. (2001). Diversity of SHV and TEM $\beta$-lactamases in Klebsiella pneumoniae: gene evolution in Northern Taiwan and two novel $\beta$-lactamases, SHV-25 and SHV-26. Antimicrob Agents Chemother 45, 2407-2413.

Coque, T. M., Oliver, A., Perez-Diaz, J. C., Baquero, F. \& Canton, R. (2002). Genes encoding TEM-4, SHV-2, and CTX-M-10 extendedspectrum beta-lactamases are carried by multiple Klebsiella pneumoniae clones in a single hospital (Madrid, 1989 to 2000). Antimicrob Agents Chemother 46, 500-510.

De Champs, C., Chanal, C., Sirot, D., Baraduc, R., Romaszko, J. P., Bonnet, R., Plaidy, A., Boyer, M., Carroy, E. \& other authors (2004). 
Frequency and diversity of class A extended-spectrum betalactamases in hospitals of the Auvergne, France: a 2 year prospective study. J Antimicrob Chemother 54, 634-639.

Deutsches Institut für Normung (1989). Methoden zur Empfindlichkeitsprüfung von mikrobiellen Krankheitserregern (außer Mykobakterien) gegen Chemotherapeutika. Teil 6: Bestimmung der minimalen Hemmkonzentration nach der Agar-Dilutionsmethode. DIN-58940-6. Berlin: Beuth-Verlag.

Domenico, P., Marx, J. L., Schoch, P. E. \& Cunha, B. A. (1992). Rapid plasmid DNA isolation from mucoid Gram-negative bacteria. J Clin Microbiol 30, 2859-2863.

Edelstein, M., Pimkin, M., Palagin, I., Edelstein, I. \& Stratchounski, L. (2003). Prevalence and molecular epidemiology of CTX-M extendedspectrum beta-lactamase-producing Escherichia coli and Klebsiella pneumoniae in Russian hospitals. Antimicrob Agents Chemother 47, 3724-3732.

Elwell, L. P. \& Falkow, S. (1986). The characterization of R plasmids and the detection of plasmid-specified genes. In Antibiotics in Labaratory Medicine, 2nd edn, pp. 683-721. Edited by V. Lorian. Baltimore: Williams and Wilkins.

Fournier, B., Lu, C. Y., Lagrange, P. H., Krishnamoorthy, R. \& Phillippon, A. (1995). Point mutation in the Pribnow-box, the molecular basis of $\beta$-lactamase overproduction in Klebsiella oxytoca. Antimicrob Agents Chemother 39, 1365-1368.

Geiss, H. K., Mack, D. \& Seifert, H. (2003). Konsensuspapier zur Identifizierung von speziellen Resistenzmechanismen und zur Interpretation von Ergebnissen der Antibiotikaempfindlichkeitstestung bei grampositiven und gramnegativen Erregern. Der Mikrobiologe 13, 222-239 (in German).

Gniadkowski, M. (2001). Evolution and epidemiology of extendedspectrum $\beta$-lactamases (ESBLs) and ESBL-producing microorganisms. Clin Microbiol Infect 7, 597-608.

Gniadkowski, M., Schneider, I., Jungwirth, R., Hryniewicz, W. \& Bauernfeind, A. (1998a). Ceftazidime resistant Enterobacteriaceae isolates from three Polish hospitals: identification of three novel TEM- and SHV-5-type extended-spectrum $\beta$-lactamases. Antimicrob Agents Chemother 42, 514-520.

Gniadkowski, M., Schneider, I., Palucha, A., Jungwirth, R., Mikiewicz, B. \& Bauernfeind, A. (1998b). Cefotaxime-resistant Enterobacteriaceae isolates from a hospital in Warsaw, Poland: identification of a new CTX-M-3 cefotaxime-hydrolyzing betalactamase that is closely related to the CTX-M-1/MEN-1 enzyme. Antimicrob Agents Chemother 42, 827-832.

Hall, T. A. (1999). BioEdit: a user-friendly biologic sequence alignment editor and analysis program for Windows 95/98/NT. Nucleic Acids Symp Ser 41, 95-98.

Heritage, J., M'Zali, F. H., Gascoyne-Binzi, D. \& Hawkey, P. M. (1999). Evolution and spread of SHV extended-spectrum $\beta$ lactamases in Gram-negative bacteria. J Antimicrob Chemother 44, 309-318.

Howard, C., van Daal, A., Kelly, G., Schooneveldt, J., Nimmo, G. \& Giffard, P. M. (2002). Identification and minisequencing-based discrimination of SHV $\beta$-lactamases in nosocomial infectionassociated Klebsiella pneumoniae in Brisbane, Australia. Antimicrob Agents Chemother 46, 659-664.

Jacoby, G. A. \& Medeiros, A. A. (1991). More extended-spectrum $\beta$ lactamases. Antimicrob Agents Chemother 35, 1697-1704.

Jeong, S. H., Kim, W. M., Chang, C. L., Kim, J. M., Lee, K., Chong, Y., Hwang, H. Y., Baek, Y. W., Chung, H. K. \& other authors (2001). Neonatal intensive care unit outbreak caused by a strain of Klebsiella oxytoca resistant to aztreonam due to overproduction of chromosomal beta-lactamase. J Hosp Infect 48, 281-288.
Kim, Y.-K., Pai, H., Lee, H.-J., Park, S.-E., Choi, E.-H., Kim, J., Kim, J. H. \& Kim, E. C. (2002). Bloodstream infections by extendedspectrum $\beta$-lactamase-producing Escherichia coli and Klebsiella pneumoniae in children: epidemiology and clinical outcome. Antimicrob Agents Chemother 46, 1481-1491.

Kim, J., Lim, Y.-M., Rheem, I., Lee, Y., Lee, J. C., Seol, S. Y., Lee, Y. C. \& Cho, D. T. (2005). CTX-M and SHV-12 beta-lactamases are the most common extended-spectrum enzymes in clinical isolates of Escherichia coli and Klebsiella pneumoniae collected from 3 university hospitals within Korea. FEMS Microbiol Lett 245, 93-98.

Kliebe, C., Nies, B. A., Meyer, J. F., Tolxdorff-Neutzling, R. M. \& Wiedemann, B. (1985). Evolution of plasmid-coded resistance to broad-spectrum cephalosporins. Antimicrob Agents Chemother 28, 302-307.

Leverstein-van Hall, M. A., Fluit, A. C., Paauw, A., Box, A. T. A., Brisse, S. \& Verhoef, J. (2002). Evaluation of the Etest ESBL and the BD Phoenix, VITEK 1 , and VITEK 2 automated instruments for detection of extended-spectrum beta-lactamases in multiresistant Escherichia coli and Klebsiella spp. J Clin Microbiol 40, 3703-3711.

Liu, C. P., Wang, N. Y., Lee, C. M., Weng, L. C., Tseng, H. K., Liu, C. W., Chiang, C. S. \& Huang, F. Y. (2004). Nosocomial and communityacquired Enterobacter cloacae bloodstream infection: risk factors for and prevalence of SHV-12 in multiresistant isolates in a medical centre. J Hosp Infect 58, 63-77.

Livermore, D. M. (1995). $\beta$-Lactamases in laboratory and clinical resistance. Clin Microbiol Rev 8, 557-584.

Mammeri, H., Laurans, G., Eveillard, M., Castelain, S. \& Eb, F. (2001). Coexistence of SHV-4- and TEM-24-producing Enterobacter aerogenes strains before a large outbreak of TEM-24-producing strains in a French hospital. J Clin Microbiol 39, 2184-2190.

Mulvey, M. R., Bryce, E., Boyd, D., Ofner-Agostini, M., Christianson, S., Simor, A. E. \& Paton, S. (2004). Ambler class A extended-spectrum beta-lactamase-producing Escherichia coli and Klebsiella spp. in Canadian hospitals. Antimicrob Agents Chemother 48, 1204-1214.

Ndugulile, F., Jureen, R., Harthug, S., Urassa, W. \& Langeland, N. (2005). Extended spectrum $\beta$-lactamases among Gram-negative bacteria of nosocomial origin from an intensive care unit of a tertiary health facility in Tanzania. BMC Infect Dis 5, 86.

Nüesch-Inderbinen, M., Hächler, H. \& Kayser, F. H. (1996). Detection of genes coding for extended-spectrum SHV betalactamases in clinical isolates by a molecular genetic method, and comparison with the E test. Eur J Clin Microbiol Infect Dis 15, 398-402.

Nüesch-Inderbinen, M., Kayser, F. H. \& Hächler, H. (1997). Survey and molecular genetics of SHV $\beta$-lactamases in Enterobacteriaceae in Switzerland: two novel enzymes, SHV-11 and SHV-12. Antimicrob Agents Chemother 41, 943-949.

Paterson, D. L., Ko, W.-C., von Gottenberg, A., Casellas, J. M., Mulazimoglu, L., Klugman, K. P., Bonomo, R. A., Rice, L. B., McCormack, J. G. \& Yu, V. L. (2001). Outcome of cephalosporin treatment for serious infections due to apparently susceptible organisms producing extended-spectrum $\beta$-lactamases: implications for the clinical microbiology laboratory. J Clin Microbiol 39, 2206-2212.

Paterson, D. L., Hujer, K. M., Hujer, A. M., Yeiser, B., Bonomo, M. D., Rice, L. B., Bonomo, R. A. \& International Klebsiella Study Group (2003). Extended-spectrum beta-lactamases in Klebsiella pneumoniae bloodstream isolates from seven countries: dominance and widespread prevalence of SHV- and CTX-M-type beta-lactamases. Antimicrob Agents Chemother 47, 3554-3560.

Péduzzi, J., Barthélémy, M., Tiwar, K., Mattioni, D. \& Labia, R. (1989). Structural features related to hydrolytic activity against 
ceftazidime of plasmid-mediated SHV-type CAZ-5 beta-lactamase. Antimicrob Agents Chemother 33, 2160-2163.

Sambrook, J., Fritsch, E. F. \& Maniatis, T. (1989). Molecular Cloning: a Laboratory Manual, 2nd edn. Cold Spring Harbor, NY: Cold Spring Harbor Laboratory.

Thomson, K. S. \& Moland, E. S. (2001). Cefepime, piperacillintazobactam and the inoculum effect in tests with extended-spectrum beta-lactamase-producing Enterobacteriaceae. Antimicrob Agents Chemother 45, 3548-3554.
Witte, W. \& Mielke, M. (2003). $\beta$-Laktamasen mit breitem Wirkungsspektrum: Grundlagen, Epidemiologie, Schlußfolgerungen für die Prävention. Bundesgesundheitsbl-Gesundheitsforsch-Gesundheitsschutz 46, 881-890 (in German).

Wu, T.-L., Siu, L. K., Su, L.-H., Lauderdale, T. L., Lin, F. M., Leu, H.-S., Lin, T.-Y. \& Ho, M. (2001). Outer membrane protein change combined with co-existing TEM-1 and SHV-1 $\beta$-lactamases lead to false identification of ESBL-producing Klebsiella pneumoniae. J Antimicrob Chemother 47, 755-761. 